\title{
Calcium to Phosphorus Ratio Measurement
}

National Cancer Institute

\section{Source}

National Cancer Institute. Calcium to Phosphorus Ratio Measurement. NCI Thesaurus.

Code C139087.

The determination of the ratio of calcium to phosphorus in a sample. The measurement may be expressed as a ratio or percentage. 